\title{
De Motu Cordis: the Lumleian Lecture of 1616 An imagined playlet concerning the discovery of the circulation of the blood by William Harvey
}

\author{
Mark E Silverman
}

J R Soc Med 2007;100:199-204

William Harvey's discovery of the circulation of blood is one of the greatest achievements in science. He sought to answer the following questions:

(1) What is the relationship of the motion of the auricle to the ventricle?

(2) Which is the systolic and which is the diastolic motion of the heart?

(3) Do the arteries pulsate because of the propulsive force of the heart?

(4) What is the purpose of the cardiac valves? . . . the venous valves?

(5) How does blood get from the right to the left ventricle?

(6) What is the direction of blood flow to and from the heart?

(7) How much blood is present in the body and how long does its passage take?

Without knowledge of the capillary circulation, Harvey concluded that ". . . the blood is driven into a round by a circular motion and that it moves perpetually; and hence does arise the action or function of the heart, which by pulsation it performs.' His revolutionary concept, first presented to the College of Physicians in 1616 and published in 1628, became accepted in his lifetime.

The following playlet is a condensed, imagined version of Harvey's De Motu Cordis, assembled from several authoritative English interpretations of his book (which was written in Latin). ${ }^{1-3}$ Notes from Harvey's lectures are available, and it appears that he did not present his finalized conception of the circulation at the public anatomy of 1616 , as depicted, but that his insights evolved over a number of Lumleian Lectures and private anatomies over a period of several years. ${ }^{4}$

Exercitatio anatomica de motu cordis et sanguinis in animalibus (An anatomical disputation of the movement of the heart and blood in animals), known as De Motu Cordis, was

Department of Medicine, Emory University School of Medicine and the Fuqua Heart Center of Piedmont Hospital, Atlanta, Georgia, USA

Correspondence: Mark E Silverman

E-mail: marksil@comcast.net finally published in 1628 as a 72 page, poorly bound paper edition containing many printing errors. ${ }^{1,5}$ Harvey's magnificent achievement-considered to be one of the greatest in science as well as the introduction of experimental observation-was controversial, but it eventually became accepted in his lifetime, except in Paris where it was severely criticized by Jean Riolan, a respected anatomist. Harvey's practice suffered initially, and, according to a comment made by Harvey, some thought he was 'crackbrained.' 6 Later, his reputation was reestablished, and he was venerated by his colleagues and the public. His practice included nobility as well as the poor, and he became a consulting physician to King James I in 1618 and the personal physician to King Charles I in 1625. When King Charles was opposed by Cromwell and the Parliament, Harvey was forced to flee with the King to Oxford. His valuable papers and notes were destroyed by the Puritan forces. After returning to London in 1646, he retired from practice at the age of 68 . In 1651, aged 73, he published Exercitationes de Generatione Animalium, a forerunner of modern embryology. When Malpighi demonstrated the capillary circulation in 1661, Harvey's circulation of the blood received its final proof, which he had postulated but was unable to prove before the microscope.

Harvey gave the Lumleian lecture intermittently until 1656, and he was active in the Royal College of Physicians as treasurer, censor, and on committees to oppose quackery and maintain standards of conduct; he declined its presidency because of ill health. He left his estate to the college and endowed its library and a museum. Harvey suffered severely from gout and, in 1657, died of a stroke at the age of 79 .

A marble bust and portrait of William Harvey, and the wand that he used to demonstrate anatomy, is on display at the Royal College of Physicians (Figure 1). The Harveian Oration continues as an esteemed annual lectureship and banquet. ${ }^{4,7}$ In 1906 the oration was delivered by William Osler, who said 'By no single event in the history of science is the growth of truth, through the slow stages of acquisition, the briefer period of latent possession, and the for us glorious period of conscious possession, better shown than in the discovery of the circulation of the blood.' 7 


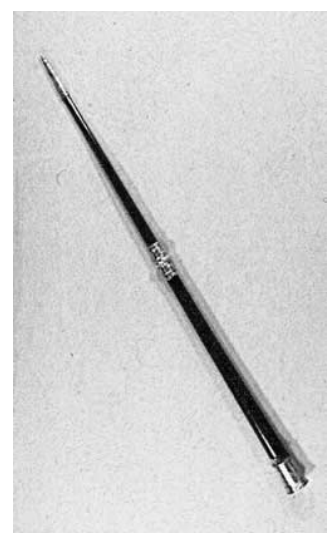

Figure 1 Wand used by William Harvey during his Lumieian demonstrations. Photograph copyright of the Royal College of Physicians of London and used with permission.

\section{INTRODUCTION OF WILLIAM HARVEY BY THE PRESIDENT OF THE COLLEGE OF PHYSICIANS}

As your President, I welcome each member of the College of Physicians to our New Anatomical Theatre and our Lumleian Lectureship on this fine spring morning of 17 April 1616. As you all know, the Guild of Surgeons united with the company of Barber Surgeons in 1540 and, by Royal Charter from Queen Elizabeth, we are allowed to perform four human dissections a year in order to improve the academic understanding of the practice of surgery. In 1582, Lord Lumley generously provided funds for these demonstrations, which are compulsory for all members to attend or they will be heavily fined. Our lecturer this year, the fourth Lumleian lecturer, is William Harvey, only 38 years old, but a Fellow of this college of nine years and already of reputation as a skilled anatomist and physician at St. Bartholomew's Hospital. We have heard rumblings that he has been conducting animal experiments of great concern to those of us who cherish the teachings of Galen. Dr Harvey is reminded that the College of Physicians is entrusted by the Crown to be the custodian of the truth of medical knowledge and that teachings to the contrary of Galen may be subject to fine. I will let him tell you about himself and to explain what he means by the curious title of his talk, 'De Motu Cordis.' Please welcome William Harvey, our Lumleian lecturer of 1616.

\section{THE LUMLEIAN LECTURE OF 1616}

Distinguished members of the College, I thank you for the honour of being your Lumleian lecturer. For my demonstration, I offer for your interest a novel concept that has occurred to me related to the purpose of the heart. We are all indebted to Claudius Galen, the revered second century Greek physician, whose teachings have been so trusted over the past 1400 years that it has been said 'Apollo practiced through the mouth of Galen,' and 'If dissection differed from Galen, it was because nature had changed.'

\section{Galen's cardiac physiology}

First, let me review for you his concepts, which are based on the theories of Hippocrates, Erasistratus, Pythagorus, and his own idea of pneuma. According to Galen, food in the intestine is concocted into chyle and transported to the liver where it becomes the venous blood. There it is endowed with the natural spirit which imparts life and nourishment as tides that ebb and flow from the liver into the veins and to all parts of the body. The vena cava carries blood to the right ventricle where some impurities are expelled into the lungs while the remainder is transported into the left ventricle via invisible pores in the ventricular septum. Pneuma, the basic principle of life, is inspired from the air into the lungs and then mixes with the purified blood in the left heart to be concocted into the vital spirit. Sooty vapors from this process are breathed out and the remaining purified blood is sent by diastolic aspiration to provide organ function. Galen taught us that diastole is the active movement of the heart which sucks venous blood into the right ventricle and air into the left. In addition, the brain adds the animal spirit which travels by the nerves to endow motion, sensation and higher function.

\section{Medicine following Galen}

After Galen, barber surgeons taught medicine at the autopsy table by reading the writings of Galen. Only crude anatomical illustrations were available and dissections were restricted by the church because of the issue of resurrection. The Renaissance, beginning in Italy in 1300, ended the Dark Ages and awakened interest in the human form and its relation to nature, as shown in the Birth of Venus, a 1485 painting by Botticelli. The printing press, introduced by Gutenberg in 1440, further disseminated new ideas. Medicine, however, remained unenlightened until the arrival of Andreas Vesalius.

\section{Andreas Vesalius and De Fabrica}

In 1543, Andreas Vesalius, that great anatomist from Brussels, aged only 28, produced his contentious masterpiece De Humani Corporis Fabrica. Vesalius corrected the anatomy of Galen, whose work was based on animal dissection, but he did not argue with Galen's physiology. Here is the frontispiece from De Fabrica, where Vesalius courageously shows himself, not the barber surgeon, conducting anatomy on a human body, not on animals which are symbolically placed away from the dissecting table (Figure 2). His magnificent anatomical illustrations 
and vivid Latin descriptions are considered to be one of the greatest achievements of the Renaissance, as well as the birth of modern medicine. However, following Vesalius, medicine was still taught by the barber surgeons reading Galen while demonstrating anatomy, as seen in Rembrandt's 1632 painting The Anatomy Lesson of Dr Tulp.

\section{The biography of William Harvey}

Now let me tell you about myself (Figure 3). I was born in Folkestone, England, on the coast of Kent, on All Fools Day 1578, one of seven sons of Thomas Harvey, a respected official. I attended Kings College Canterbury at age 10, and then Caius College Cambridge, on scholarship. At the age of 19, I enrolled in the respected medical school at Padua, that great Italian centre founded in 1222, where Vesalius, Columbus, Cesalpino and Galileo taught so well. My professor was Fabricius d'Aquapendente, whose interest in the venous valves so stimulated my conclusions to be set forward today. I graduated with honours in 1602, returning to London to practice in 1603, and married Elizabeth Browne in 1604. In 1607, I was elected a fellow in the College of Physicians. Since 1609, I have been an attending physician at St. Bartholomew's Hospital.

\section{The development of the concept that blood circulates}

Since my return to England, I have dissected and observed more than 80 species of animals in my laboratory. I did my best to approach these experiments unbiased by the teachings of Galen: not from books but from dissections; not from the positions of philosophers but from the fabric of nature do I profess to learn and to teach.

First, I seriously considered how much blood might be lost from cutting the arteries. Then I reflected on the symmetry and the similar size of the vessels entering and leaving the ventricles of the heart, for Nature would not have given these vessels such relative greatness uselessly. Then I thought of the arrangement and structure of the valves and the rest of the heart. For a long time I turned over in my mind such questions as how much blood is transmitted, and how short a time its passage doth take. Not deeming it possible for the digested food mass to furnish such an abundance of blood without rupturing the arteries, unless it somehow got back to the veins from the arteries and returned to the right ventricle of the heart, I began to think there was a sort of motion, as in a circle (Box 1).

\section{The motion of the heart is timed}

First I had to time the motion of the heart. When I first applied my mind to observation that I might find out the use of the motion of the heart, I found it so truly difficult that I did almost believe that the motion of the heart was known

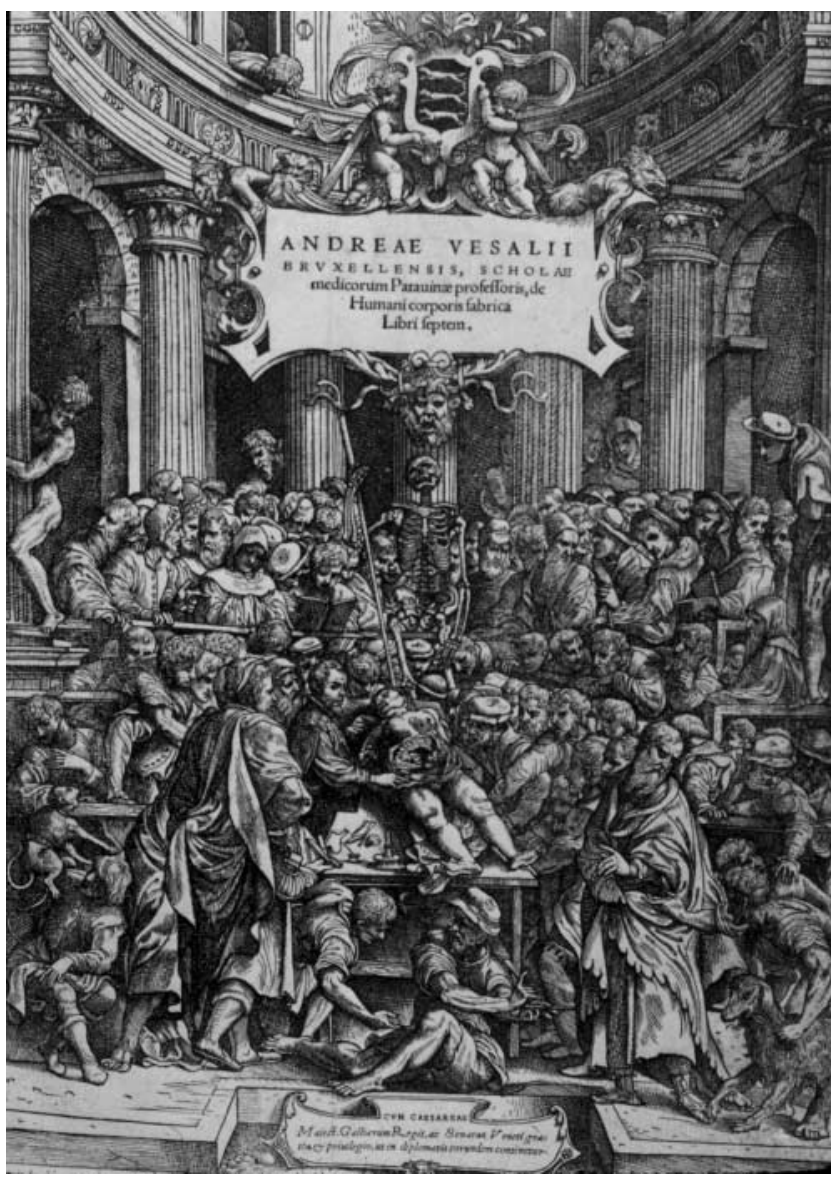

Figure 2 Frontispiece from "De humani Corporis Fabrica". Vesalius places himself at the center conducting the autopsy. Animals are shown at the extreme sides and the barber surgeons are under the dissecting table to indicate symbolically that the medieval approach is no longer suitable. The articulated skeleton at the top represents death.

to God alone. In many animals this takes place in the twinkling of an eye, like a flash of lightning. I observed that it is the pulsation of the auricles that sends the blood into the ventricles. After the heart has left beating, and the ears [auricles] are beating still, if you cut off the tip of the heart with scissors, you will see the blood gush out at each beat of the auricles. This shows how blood enters the ventricles, not by the suction or dilatation of the ventricles, as Galen stated, but by the beat of the auricles.

\section{The apical impulse is due to contraction not dilatation}

I suspected that the chief function of the heart is to pump blood through the arteries and that the pulse is due to the blood conveyed from the heart. I discovered that the motion which is commonly thought the diastole of the heart is really the systole, and therefore the apical impulse is due to the contraction, not the dilation, of the heart. Let me show you: at the moment of systole, the heart feels harder, 


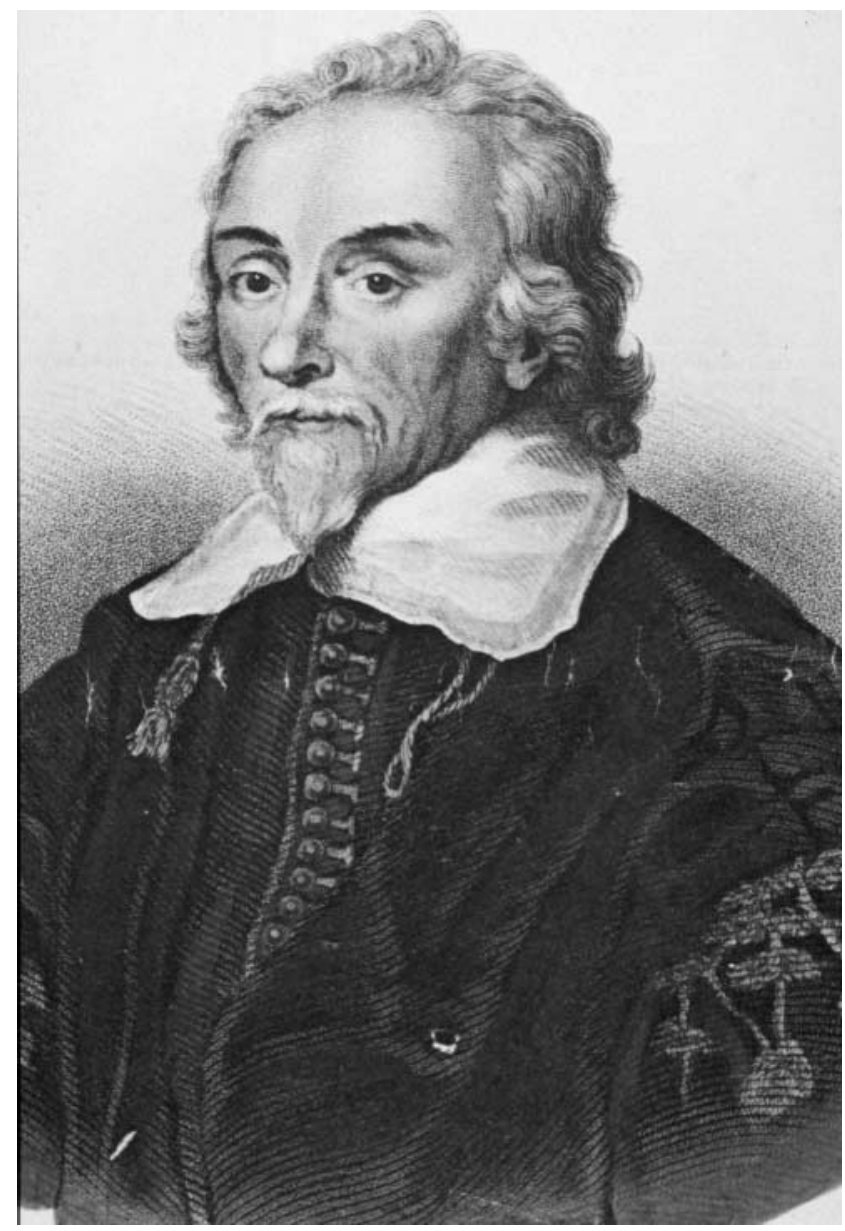

Figure 3 William Harvey, engraving by Cornelius Jansen, 1878.

contracts, is lifted up and strikes the chest wall, at which moment the apex beat can be felt. It is reasonable to conclude that the heart at the moment it acts, becomes constricted all over, thicker in its walls and smaller in its ventricles, in order to expel its content of blood. With each movement of the heart, a pulse is made which may be heard in the chest.

\section{The heart is the propulsive force}

I had to prove that the heart is the propulsive force behind the circulation. If you cut the vessel which leads from the heart, you will see the blood forcibly thrust out through the cut at the very moment that the heart is tensed. From this it is clear that the arteries are distended by reason of the enthrusting of blood by the constriction of the ventricles. All the arteries of the body pulsate because of the same cause - the contraction of the left ventricle.

\section{The valves promote the forward movement of the blood}

In addition, the ingenious arrangement of the valves doth promote the forward movement of the blood. There are in
Box 1 Questions regarding the heart.

(1) What is the relationship of the motion of the auricle to the ventricle?

(2) Which is the systolic and which is the diastolic motion of the heart?

(3) Do the arteries pulsate because of the propulsive force of the heart?

(4) What is the purpose of the cardiac valves? . . the venous valves?

(5) How does blood get from the right to the left ventricle?

(6) Which is the direction of blood flow to and from the heart?

(7) How much blood is present and how long does its passage take?

the orifice of the pulmonary artery three doors which prevent the blood sent into the pulmonary artery from returning again to the heart. So likewise in the aorta. When they are raised and tightly joined, they form a three pointed line, and the more tightly they are forced shut, the more they block the reflux of blood.

\section{There are no invisible pores in the ventricular septum}

I found no invisible pores in the septum and postulated that the blood travels from the right ventricle to the pulmonary artery through the lungs and then to the left side of the heart. That opinion is not to be tolerated which doth assert that the blood seeps through hidden pores in the septum of the heart out of the right ventricle into the left. But damn it, no such pores exist nor can they be demonstrated! Why require invisible pores and obscure channels to get the blood to the left ventricle when there is such a wide open passage through the pulmonary veins?

\section{The direction of blood flow is demonstrated}

Blood passes from the right ventricle of the heart through the pulmonary artery to the lungs, and from there through the pulmonary vein into the left auricle and then into the left ventricle. I shall show how this may be so: water injected through the vena cava into the right ventricle, all the other vessels of the heart being ligatured, merely distends the right ventricle and does not flow through a cut made in the left ventricle, whereas if water be injected through the pulmonary artery it immediately gushes out from the hole in the left ventricle. 


\section{The veins carry blood to the heart and the arteries away}

It is obvious that blood enters a limb through the arteries and returns through the veins. Pinching off the vena cava with a pair of forceps, the course of blood being intercepted some distance below the heart, you will see that the space between your forceps and the heart is drained at once, the blood being emptied by the heartbeat. The heart becomes much paler, smaller from lack of blood and beats more slowly. Immediately on releasing the vein, the colour and size of the heart returns to normal. Afterwards, if you ligate or compress the artery a little distance above the heart, you will see the space between the compression and the heart becomes greatly distended and of a purple colour. On removing the block, the normal colour, size and pulse return

A tight and then middling ligature of the arm also shows the direction of the arterial and venous circulation

Place on a ligature, as tightly as the subject can stand. It may be observed that the artery does not pulsate beyond the bandage. The hand, however, retains its normal colour and appearance. After this bandage has been on for some time, loosen it to medium tightness. You will see the whole hand at once becomes suffused and distended, and its veins impacted and engorged. You will see the hand become exceedingly gorged with a great amount of blood. From these facts any careful observer may easily understand that blood enters a limb through the arteries.

\section{The anatomy of the venous valves provides critical evidence}

The orientation of the venous valves, as taught to me by my teacher, Fabricius, provided an inspiration. By passing a probe both directions into the veins, the correct direction of venous blood flow can be shown. I have often noticed in dissecting veins, it is impossible to pass a probe from the main venous trunks very far into the smaller branches on account of the valvular obstructions. On the contrary it is very easy to push it in the opposite direction, from the branches toward the larger trunks. The venous valves oppose any movement of blood from the larger veins toward the smaller ones, but they favour and facilitate a free and open route starting from the small veins and ending in the larger ones.

\section{The quantity of blood must be fixed}

My further analysis shows that the quantity of the blood must be fixed and cannot be continuously formed in the liver. Let us suppose how much blood the left ventricle may contain in its dilatation - say two or three ounces. Let us suppose likewise how much less the heart may contain in its contraction. And from thence how much blood is thrust out into the aorta. The heart in one-half hour makes about a thousand pulses. Now multiply the drams passed through the heart into the arteries and you will always find the greater quantity than can be found in the whole of the body. It is clear that more blood continually flows through the heart than can be supplied by the digested food or be held in the veins at one time unless by constantly making a circuit and returning. By cutting a single artery, all the blood may be easily drained from the whole body in a half hour's time. Therefore, the blood content is not continually formed but must be fixed.

\section{Conclusion}

And now let me put forward my opinion concerning the circulation of the blood. Seeing it is confirmed by reasons and ocular experiments, it must be of necessity concluded that the blood is driven into a round by a circular motion and that it moves perpetually; and hence does arise the action or function of the heart, which by pulsation it performs. All these phenomena and many others noted in dissecting seem clearly to illustrate and to confirm the truth announced and at the same time to refute popular opinion. It would be hard to explain in any other way why all these matters were so made and constituted except in a manner conforming to my theory and to what I have expounded.

\section{Final comment}

Dear friends and trusted colleagues of the College. What remains to be said on the quantity and source of this transferred blood, is so strange and undreamed of that not only do I fear danger to myself from the malice of a few, but I dread lest I have all men as enemies, so much does habit or doctrine once absorbed become second nature, and so much does reverence for antiquity influence all men. But now the die is cast: my hope is in your love of truth and in the integrity of your intelligence. I thank you for your kind attention.

\section{Competing interests None declared.}

Acknowledgments I thank Arthur Hollman of Sussex, England for sharing his knowledge of the Royal College of Physicians of London, Kyle Petersen of the Department of Anatomy at Emory University for his support, and the Wellcome Library for the History of Medicine for their resources.

Footnote This playlet has been delivered yearly since 1971 to the Emory University School of Medicine freshman anatomy class as an entertaining method of teaching medical history and cardiac anatomy and function. Harvey's experiments were magnificently recreated by the Royal 
College of Physicians and short segments are shown by PowerPoint presentation to illustrate the answers to the questions posed by Harvey.

\section{REFERENCES}

1 Leake CD. Exercitatio Anatomica De Motu Cordis Et Sanguinis In Animalibus (Anatomical Studies on the Motion of the Heart and Blood) by William Harvey: An English Translation with Annotations. Springfield, Illinois: Charles C Thomas, 1929

2 The Classics of Medicine Library. William Harvey: Exercitatio Anatomica De Motu Cordis Et Sanguinis In Animalibus: Being a Facsimile of the 1628
Francofurti Edition Together with the Keynes English Translation of 1928. Birmingham: Classics of Medicine, 1978

3 Whitteridge G. William Harvey and the Circulation of the Blood. New York: American Elsevier, 1971

4 Davenport G, McDonald I, Moss-Gibbons C. The Royal College of Physicians and its Collections. London: James and James Ltd, 2001

5 Prieur GO. William Harvey. Historical Bulletin of the Calgary Clinic 1952; 17:2130

6 Jarcho S. William Harvey described by an eyewitness (John Aubrey). Am J Cardiol 1958;3:381-4

7 Osler W. The Growth of Truth: As Illustrated in the Discovery of the Circulation of the Blood. London: Henry Drowde, 1906 